\title{
Inflammatory myofibroblastic tumor
}

INSERM

\section{Source}

INSERM. (1999). Orphanet: an online rare disease and orphan drug data base.

Inflammatory myofibroblastic tumor. ORPHA:178342

Inflammatory myofibroblastic tumor is a rare neoplastic lesion of the submucosal stroma, which can develop in any organ, often occurring in the lung, mesentery, omentum and the retroperitoneal region. It is histologically heterogenous, composed of spindle-shaped cells, myofibroblasts and inflammatory cells. It is usually benign, however local invasion, recurrence, malignant transformation with vascular invasion and metastases may occur. The presentation is nonspecific and depends on the organ involved. Some patients may present with paraneoplastic syndrome (fever, malaise, weight loss, anemia, thrombocytosis) or symptoms related to compression of adjacent organs, such as bowel obstruction. 